\title{
IMPLEMENTASI MOTOR SERVO SG 90 SEBAGAI PENGGERAK MEKANIK PADA E. I. HELPER (ELECTRONICS INTEGRATION HELMET WIPER)
}

\author{
IMPLEMENTATION OF THE SERVO SG 90 MOTOR AS A \\ MECHANICAL DRIVE IN E. I. HELPER (ELECTONICS \\ INTEGRATION HELMET WIPER)
}

\author{
Akhmad Irfansyah Salim 1 ${ }^{1}$, Yuliarman Saragih $2^{2}$, Rahmat Hidayat $3^{3}$ \\ ${ }^{123}$ Universitas Singaperbangsa Karawang \\ 1 akhmad.irfansyahsalim16015@student.unsika.ac.id 1, ${ }^{2}$ yuliarman@staff.unsika.ac.id 2, \\ rahmat.hidayat@staff.unsika.ac.id 3
}

\begin{abstract}
Abstrak
Banyaknya pengguna pengendara sepeda motor di hadapkan masalah ketika hujan turun, jarak pandang kaca helm yang tebatas ketika mengemudi bisa menjadi salah satu faktor yang menyebabkan terjadinya kecelakaan berlalu lintas. Wiper Helm atau E. I. Helper adalah alat bantu pada pengendara sepeda motor yang mempunyai fungsi untuk membersihkan kaca helm dari jarak pandang yang terbatas ketika hujan turun, dengan menyesuaikan perhitungan pengukuran sudut $0^{0}-110^{\circ}$, dengan waktu delay durasi rata - rata 3,35 detik untuk membersihkan permukaan kaca helm secara bolak balik pada sistemnya, percobaan di lakukan selama 9 kali pada kaca helm dengan tingkat keberhasilan pengujian yang stabil. Pada sistem pergerakan mekanik E. I. Helper yang sudah di program data melalui aplikasi Arduino IDE, digunakan sistem penggerak mekanik Motor Servo SG 90 dan Mikrokontroler Arduino Nano Atmega 328. Penggerak mekanik Motor Servo SG 90 pada rangkaian E. I. Helper akan berstatus aktif daya listrik mengalir dengan saklar push button kondisi ON sedangkan rangkaian E. I. Helper akan berstatus tidak aktif pada kondisi saklar push button OFF.
\end{abstract}

Kata kunci : E. I. Helper, Penggerak Meknaik, Motor Servo SG 90

\begin{abstract}
Many motorcyclists face problems when it rains, visibility limited helmet glass when driving can be one of the factors that cause it traffic accidents. Wiper Helm or E. I. Helper is a tool for motorcyclists which has a function to clean the helmet glass from a limited visibility when it rains down, by adjusting the measurement angle calculation $0^{0}-110^{\circ}$, with the average duration delay time 3.35 seconds to clean the surface of the helmet glass back and forth on the system, experiment on do 9 times on the helmet glass with a stable test success rate. On the system E. I. Helper mechanical movements that have been programmed data through the Arduino IDE application, are used mechanical drive system Servo Motor SG 90 and Microcontroller Arduino Nano Atmega 328. The SG 90 servo motor mechanical drive in the E. I. Helper series will have an active electrical power status flows with the push button switch ON condition while the E. I. Helper circuit will have no status active when the push button switch is OFF.
\end{abstract}

Keywords: E. I. Helper, Mechanical Drive, Servo Motor SG 90 
Jurnal Electro Luceat [November] [2020]

\section{PENDAHULUAN}

Pengguna moda transportasi di hadapkan dengan berbagai masalah ketika hujan turun, salah satunya moda transportasi darat pada penggunaan sepeda motor. Dalam mengendarai kendaraan bermotor keselamatan berlalu - lintas adalah hal yang sangat penting untuk di jaga agar kita dan orang lain terhindar dari kecelakaan berlalu - lintas. Ada beberapa faktor terjadinya kecelakaan seperti kelalaian, pengguna jalan, ketidaklayakan kendaraan, jalan atau lingkungan. Dalam berkendara salah satunya penglihatan jarak pandang kaca helm yang terbatas pun juga bisa menyebabkan kecelakaan ketika hujan turun.

Dari faktor permasalahan di atas, jarak pandang pada kaca helm yang menyebabkan kecelakaan, penulis memiliki ide gagasan untuk membuat sebuah terobosan di bidang teknologi dengan menerapkan standar keamanan berkendara yaitu E. I. Helper.

Sistem pergerakan mekanik yang digerakan dengan Motor Servo SG 90 ini nantinya akan bekerja pada E. I. Helper berfungsi untuk membersihkan air hujan pada kaca helm yang sangat mengahalangi jarak pandang pengendara ketika hujan turun. Sehingga pengendara sepeda motor dapat melaju dengan baik selama hujan dengan menggunakan helm.

\section{DASAR TEORI /MATERIAL DAN METODOLOGI/PERANCANGAN}

\subsection{Dasar Teori}

\subsubsection{Motor Servo SG 90}

Motor servo adalah sebuah motor dengan sistem closed feedback di mana posisi dari motor akan di informasikan kembali ke rangkaian kontrol yang ada di dalam motor servo [1]. Dengan input ke kontrolnya yang bisa berupa sinyal analog ataupun sinyal digital, pada dasarnya motor servo banyak digunakan sebagai aktuator yang membutuhkan posisi putaran motor yang presisi. Sedangkan sudut dari sumbu motor servo diatur berdasarkan lebar pulsa yang dikirim melalui kaki sinyal dari kabel motor. Motor Servo biasanya hanya bergerak mencapai sudut tertentu saja dan tidak secara kontinyu, Namun untuk beberapa keperluan Motor Servo dapat dimodifikasi bergerak secara kontinyu [2]. Komponen Potentisiometer pada Motor Servo SG 90 berfungsi untuk menentukan batas maksimum putara sumbu (axis) moto servo [3].

\subsubsection{Arduino Nano}

Arduino Nano merupakan suatu papan pengembang mikrokontroler yang menggunakan chip ATmega328P, Arduino Nano bekerja pada masukan tegangan 5-7 Volt [4]. Arduino Nano memuat semua yang dibutuhkan untuk menunjang mikrokontroler, mudah menghubungkannya ke sebuah komputer dengan sebuah kabel USB atau mensuplainya dengan sebuah adaptor AC ke DC atau menggunakan baterai untuk memulainya [5].

\subsubsection{Push Button}

Push button switch (saklar tombol tekan) adalah perangkat/saklar sederhana yang berfungsi untuk menghubungkan atau memutuskan aliran arus listrik dengan sistem kerja tekan unlock (tidak mengunci) [6]. Sesuai dengan namanya, saklar push button fungsinya adalah untuk memutuskan atau menghubungkan aliran listrik dengan cara ditekan bagian tombolnya. Saklar ini termasuk jenis saklar kontak tukar yang dalam operasinya disesuaikan dengan penggunaanya.

Normally Open (NO), saklar berfungsi sebagai normal buka dan berfungsi untuk menghubungkan arus menuju suatu beban

Normally Close (NC), saklar berfungsi sebagai normal tutup dan berfungsi untuk memutuskan arus ke beban [7]. 


\subsection{Metodologi Dan Perancangan}

\subsubsection{Metodologi}

Pada metodologi penelitian yang di gunakan di tampilkan flowchart penelitian pada gambar 1.

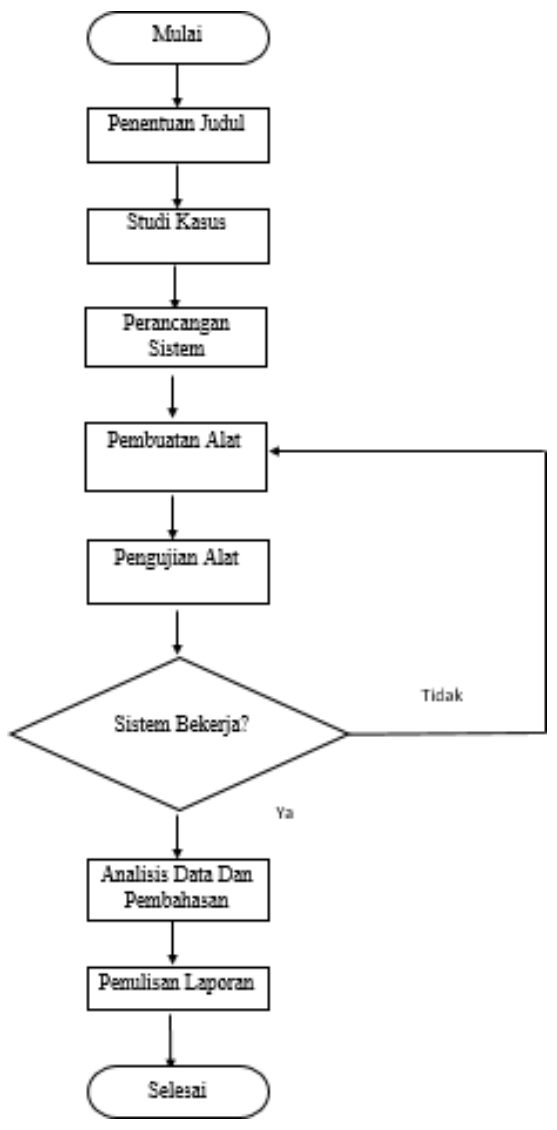

Gambar 1. Flowchart Penelitian

\subsubsection{Perancangan}

Pada tahap perancangan sistem Motor Servo SG 90 sebagai penggerak wiper, mikrokontroler arduino nano akan mengoperasikan melalui input data dan memberikan perintah kepada Motor Servo SG 90 untuk melakukan pergerakan mekanik sesuai input operasi sudut yang di inginkan. Diantaranya meliputi perancangan :

\subsubsection{Blok Diagram Sistem}

Berikut rancangan blok diagram yang di gunakan pada perancangan E. I. Helper sebagai berikut. 


\section{Jurnal Electro Luceat [November] [2020]}

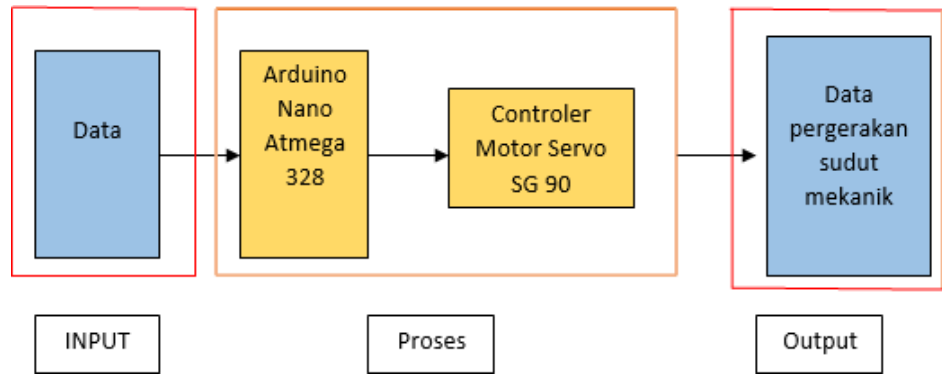

Gambar 2. Blok Diagram Sistem E. I. Helper

Tabel 1. Sistem Operasi E. I. Helper

\begin{tabular}{|c|l|}
\hline Tahapan & \multicolumn{1}{c|}{ Keterangan } \\
\hline Input & $\begin{array}{l}\text { Masukan data berupa source code dari aplikasi program Arduino IDE yang nantinya } \\
\text { untuk menjalankan ke tahap berikutnya pada E. I. Helper. }\end{array}$ \\
\hline Proses & $\begin{array}{l}\text { Arduino Nano Atmega 328 sebagai mikrokontroler akan memproses masukan data } \\
\text { source code berupa pergerakan mekanik pada controler Motor Servo SG 90 }\end{array}$ \\
\hline Output & $\begin{array}{l}\text { Data pegerakan sudut mekanik ini nantinya akan menjalankan E. I. Helper untuk } \\
\text { melanjutkan fungsi membersihkan kaca helm pada kendaraan bermotor dari jarak } \\
\text { pandang yang terbatas. }\end{array}$ \\
\hline
\end{tabular}

\subsubsection{Desain 3D Prdouk E. I. Helper}

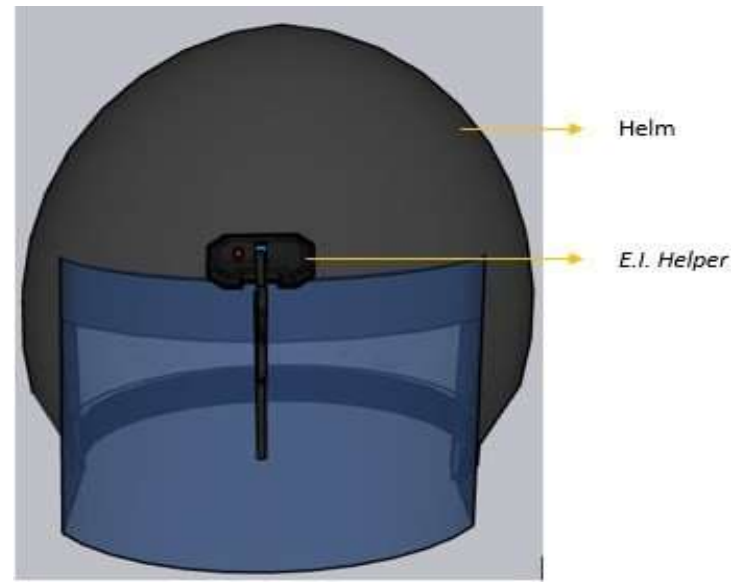

Gambar 3. Desain E. I. Helper Tampak Depan

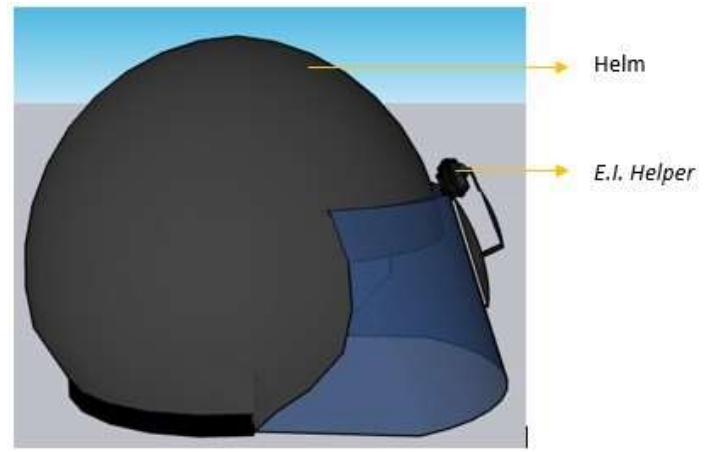

Gambar 4. Desain E. I. Helper Tampak Samping 
Jurnal Electro Luceat [November] [2020]

Pada gambar 3 dan 4 di perlihatkan gambar desain tampak depan dan samping pada E. I. Helper keterangan pada gambar di jelaskan penggunaan Helm Half Face untuk alat bantu di sematkannya E. I. Helper dan pada E. I. Helper nantinya terdiri dari beberapa komponen rangkaian diantaranya dengan fungsi :

a. Motor Servo SG 90 : Sebagai pengatur pergerakan mekanik sudut dari E. I. Helper dengan rentang sudut $0^{0}-110^{\circ}$.

b. Wiper : Merupakan alat pembantu yang sudah terkait dengan Motor Servo SG 90 nantinya akan membersihkan permukaan kaca helm dari jarak pandang yang terbatas ketika hujan.

c. Arduino Nano : Merupakan Mikrokontroler pada E. I. Helper, Peran Mikrokontroler Arduino juga berfungsi sebagai pengolah data dan pengatur semua aktivitas yang di buat [8].

d. Box : Merupakan tempat keseluruhan dari komponen E. I. Helper, Dengan kabel Jumper yang dipergunakan untuk menghubungkan satu komponen dengan komponen lain ataupun menghubungkan jalur rangkaian yang terputus pada papan breadboard [9].

e. Push Button : Merupakan Saklar yang berfungsi untuk menghubungkan atau memutuskan aliran arus listrik pada E. I. Helper.

f. Baterai 9V : Pada E. I. Helper, Bagian catu daya pada sistem berfungsi mensuplay tegangan pada masing - masing komponen sehingga rangkaian dapat bekerja [10].

\subsubsection{Flowchart Sistem Pergerakan Mekanik}

Berikut rancangan flowchart sistem pergerakan mekanik E. I. Helper sebagai berikut. Pada awal tombol push button menandakan 2 opsi pilihan yaitu ketika posisi push button di tekan kondisi awal on, supply arus daya listrik masuk dan menghidupkan E. I. Helper maka input data sudut Motor Servo SG 90 akan di proses pada mikrokontroler arduino nano untuk selanjutnya di olah menjadi output keluaran motor servo yang bergerak secara mekanik pada E. I. Helper. Dan jika push button ditekan kembali posisi off maka supply arus daya listrik tidak mengalir dan E. I. Helper berhenti atau mati.

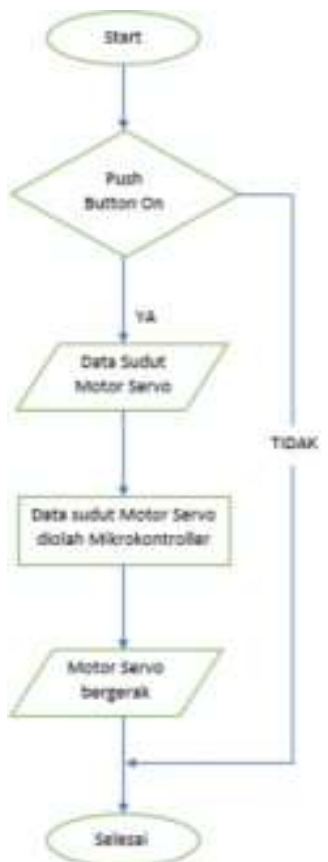

Gambar 5. Flowchart sistem penggerak mekanik pada E. I. Helper 


\section{HASIL DAN PEMBAHASAN}

Pada bagian ini di lakukan proses pengujian implementasi Motor Servo SG 90 pada E. I. Helper meliputi :

\subsection{Implementasi Tahap Hardware}

Pada implementasi tahap hardware rancangan di uji dengan melihat ketentuan sudut kestabilan dengan memperhatikan ketelitian serta parameter - parameter yang akan di uji berikut tampilan hardware E. I.. Helper :

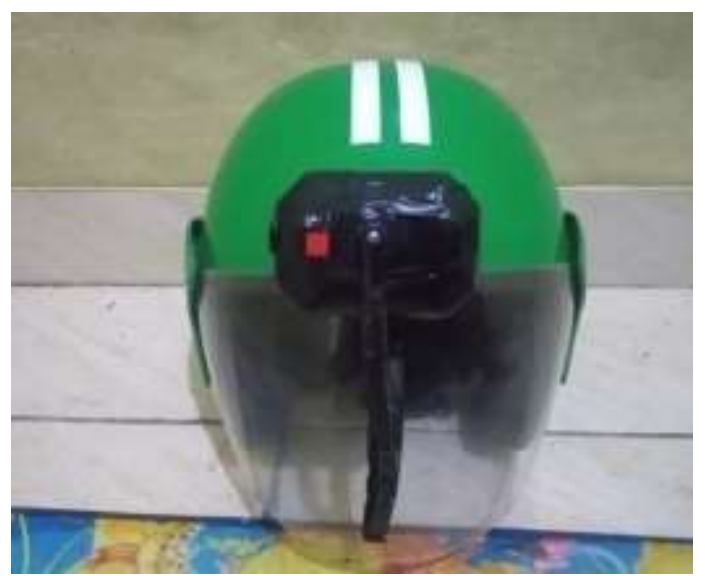

Gambar 6. E. I. Helper Tampak Depan

\subsection{Pengujian}

\subsubsection{Pengujian Ketelitian Sudut Motor Servo SG 90}

Pengujian ketelitian sudut pada Motor Servo SG 90 dilakukan secara bertahap untuk mendapatkan sudut yang di inginkan pada wiper agar bekerja secara baik dan dimulai dengan pengukuran sudut yang di uji yaitu $0^{0}, 30^{\circ}, 45^{0}, 60^{\circ}, 90^{\circ}, 110^{\circ}$ dilakukan untuk menganalisis sudut dari Motor Servo SG 90 dengan menggunakan busur untuk mengetahui tingkat kestabilan akurasi kendali mikrokontroler terhadap servo. Berikut hasil pengujian kestabilan ketelitian sudut pada Motor Servo SG 90 ditunjukkan pada gambar 7.

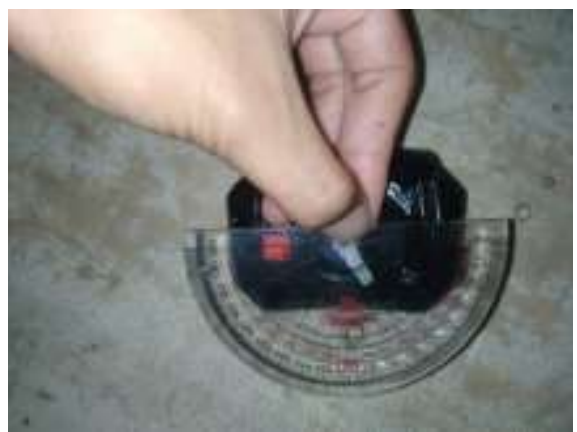

Gambar 7. Pengujian secara manual sudut Motor Servo SG 90 dengan busur

Setelah di lakukan pengujian secara bertahap di dapatkan hasil data pengukuran dengan tingkat pengaruh kestabilan seperti pada tabel 2 . 
JEC Vol. 6 No. 2

Jurnal Electro Luceat [November] [2020]

Tabel 2. Pengujian ketelitian sudut Motor Servo SG 90

\begin{tabular}{|l|c|c|c|}
\hline $\begin{array}{c}\text { No } \\
\text { Percobaan }\end{array}$ & $\begin{array}{c}\text { Pengukuran Secara } \\
\text { Manual dengan } \\
\text { busur }\end{array}$ & $\begin{array}{c}\text { Sudut yang } \\
\text { dinginkan }\end{array}$ & $\begin{array}{c}\text { Persentase } \\
\text { Kesalahan } \\
\%\end{array}$ \\
\hline 1 & $0^{0}$ & $0^{0}$ & 0 \\
\hline 2 & $34^{0}$ & $30^{0}$ & 13,3 \\
\hline 3 & $49^{0}$ & $45^{0}$ & 8,9 \\
\hline 4 & $64^{0}$ & $60^{0}$ & 6,7 \\
\hline 5 & $94^{0}$ & $90^{0}$ & 4,4 \\
\hline 6 & $114^{0}$ & $110^{0}$ & 3,63 \\
\hline \multicolumn{3}{|c|}{ Rata - rata kesalahan } \\
\hline
\end{tabular}

Berdasarkan dari hasil data yang di dapat dari penentuan source code pada aplikasi arduino IDE ke Motor Servo SG 90 , terdapat perbandingan perbedaan hasil sebelum dan sesudah pengukuran dengan rata - rata persentase kesalahan di dapat 33,9\% untuk tingkat pengujian ketelitian.

\subsubsection{Pengujian kestabilan Motor Servo SG 90 dengan torsi beban kerangka wiper pada E. I.} Helper

Pengujian di lakukan untuk melihat kestabilan dari Motor Servo SG 90 dengan torsi beban wiper ketika di uji pada E. I. Helper terlihat pada gambar 8 dan 9 :

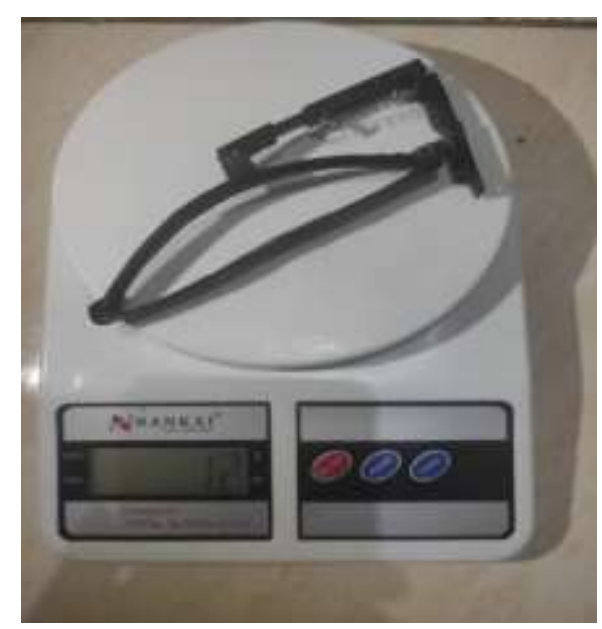

Gambar 8. Berat timbangan kerangka wiper

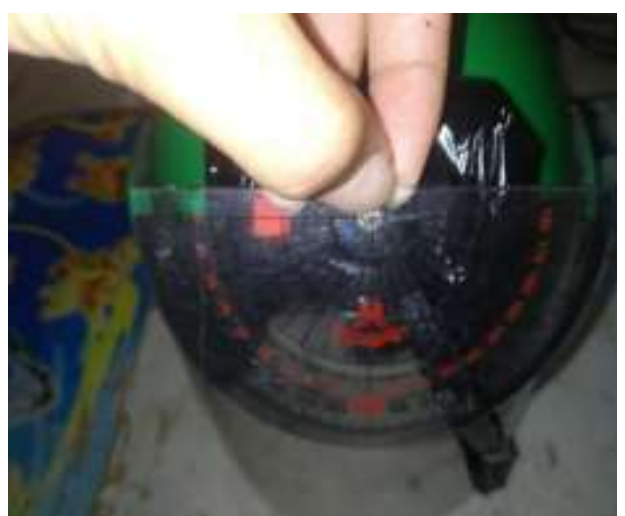

Gambar 9. Pengujian kestabilan Motor Servo SG 90 dengan beban wiper 
Jurnal Electro Luceat [November] [2020]

Setelah di lakukan percoban di dapatkan besar data pengaruh tingkat kestabilan Motor Servo SG 90 dengan torsi beban wiper pada E. I. Helper seperti pada Tabel 3.

Tabel 3. Pengujian Motor Servo SG 90 dengan torsi beban wiper menyesuaikan sudut pada kaca helm $\left(40^{\circ}\right.$ -

$$
150^{\circ} \text { ) bolak - balik }
$$

\begin{tabular}{|l|c|c|c|c|}
\hline $\begin{array}{c}\text { No } \\
\text { Percobaan }\end{array}$ & $\begin{array}{c}\text { Pengukuran gerak } \\
\text { sudut secara manual } \\
\text { dengan busur pada } \\
\text { Motor Servo SG 90 }\end{array}$ & $\begin{array}{c}\text { Waktu } \\
\text { pergerakan } \\
\text { Source Code } \\
\text { Arduino IDE }\end{array}$ & $\begin{array}{c}\text { Pengukuran } \\
\text { waktu } \\
\text { pergerakan } \\
\text { sudut } \\
\text { (Stopwatch) }\end{array}$ & Error (\%) \\
\hline 1 & Stabil & 3,3 detik & 3,5 detik & 6,06 \\
\hline 2 & Stabil & 3,3 detik & 3,3 detik & 0 \\
\hline 3 & Stabil & 3,3 detik & 3,2 detik & 3,03 \\
\hline 4 & Stabil & 3,3 detik & 3,4 detik & 3,03 \\
\hline 5 & Stabil & 3,3 detik & 3,4 detik & 3,03 \\
\hline 6 & Stabil & 3,3 detik & 3,4 detik & 3,03 \\
\hline 7 & Stabil & 3,3 detik & 3,3 detik & 0 \\
\hline 8 & Stabil & 3,3 detik & 3,3 detik & 0 \\
\hline 9 & Stabil & 3,3 detik & 3,4 detik & 3,03 \\
\hline & Rata - rata & 3,3 detik & 3,35 detik & 2,35 \\
\hline
\end{tabular}

Pada tabel di atas di dapat data pengujian Motor Servo SG 90 menunjukan waktu delay stopwatch yang berubah - ubah dengan tingkat keberhasilan alat yang stabil dengan range 00.03.2 00.03.5 serta rata - rata 3,35 detik pada waktu perhitungan dengan beban wiper dan juga error 2,35\%

\section{KESIMPULAN DAN SARAN}

\subsection{KESIMPULAN}

Berdasarkan hasil penelitian yang telah di lakukan dapat di tarik kesimpulan di atas :

1. Peran Motor Servo SG 90 sebagai implementasi penggerak mekanik pada E. I. Helper dapat menjalankan fungsinya dengan rentang sudut $0^{0}-110^{\circ}$ dengan tingkat kestabilan yang baik.

2. Untuk membersihkan kaca helm motor, E. I. Helper memerlukan waktu dengan rata - rata 3,35 detik pada pergerakan wipernya dengan menyesuaikan sudut $40^{\circ}-150^{\circ}$ ketika di pasangkan pada helm, sesuai pengukuran manual busur di dapat selisih $\left(110^{\circ}\right)$.

\subsection{SARAN}

Berdasarkan hasil penelitian, Saran ini di tujukan untuk pengembangan alat berikutnya. Sehingga di harapkan dapat memperbaiki kekurangan dari penelitian ini :

1. Penambahan parameter sensor - sensor agar alat memiliki lebih banyak fitur dan fungsi

2. E. I.Helper perlu di kembangkan terkait penggerak kecepatan pembersih kaca wiper, serta fitur anti air agar lebih baik dari sebelumnya.

\section{DAFTAR PUSTAKA}

[1] Hilal, A., dan Manan, S., (2013), "Pemanfaatan Motor Servo sebagai Penggerak CCTV untuk Melihat Alat-Alat Monitor dan Kondisi Pasien di Ruang ICU", Gema Teknologi, vol. 17, no.2.

[2] Rinaldy, Christianti, R. F., dan Supriyadi D., (2013), "Pengendalian Motor Servo Yang Webcam Berbasi Internet Dan Arduino", Jurnal Infotel, vol. 5. 
[3] Latifa, U., dan Saputro, J. S., (2018), "Perancangan Robot Arm Gripper Berbasis Arduino Uno Menggunakan Antarmuka Labview”, Jurnal Barometer, vol.3, no.2, pp. 138 - 141.

[4] Kurniawan, A. H., dan Rivai, M., (2018), “ Sistem Stabilisasi Nampan Menggunakan IMU Sensor dan Arduino Nano", Jurnal Teknik ITS, vol. 7.

[5] Muchtar, H., dan Hidayat, A., (2017), "Implementasi Wavecom Dalam Monitoring Beban Listrik Berbasis Mikrokontroler" Jurnal Teknologi, vol. 9 no.1.

[6] Eriyani, V., Triyanto, D., dan Nirmala, I., (2018), "Rancang Bangun Robot Pelayan Restoran Otomatis Berbasis Mikrokontroler ATMEGA 16 Dengan Navigasi Line Follower", Coding Sistem Komputer Untan, vol. 6, no. 3, pp. 66 - 74.

[7] Hamrul, H., Waluyo, A., dan Busyran, M., (2011), "Rancang Bangun Alat Pengontrolan Daur Ulang Solar Bekas Dengan Mikrokontroler AT89C51” Jurnal Ilmiah D’ComPutarE, vol.1

[8] Saragih, Y., Hakim G. R., Elisabet A., dan Roostiani H. A., (2019), "Monitoring Design of Methods and Contents Methods in Semi Real Water Tandon by Using Arduino-based on Internet of Things", IEEE, pp. 1- 4.

[9] Nusyirwan, D., Aritonang, M. D., dan Perdana P. P . P, (2019), "Penyaringan Air Keruh Menggunakan Sensor LDR dan Bluetoth HC - 05 Sebagai Media Pengontrolan Guna Meningkatkan Mutu Kebersihan Air di Sekolah”, Logista Jurnal Imiah Pengabdian Kepada Masyarakat, vol. 3, no.1.

[10] Hidayat, R., (2017), "Pengembangan Alat Ukur Kadar Air Padi (GABAH) Untuk Mewujudkan Pertanian Industrial Di Kabupaten Indramayu, "Creative Research Jurnal, vol. 2, no. 1, pp. 55 -68 . 